\title{
INVESTIGATION OF THE DYNAMICS OF THE VISCOSITY OF MODEL SYSTEMS OF THE CROQUETTE MASS BASED ON FLOUR AT HYDROTHERMAL PROCESSING
}

\author{
Tetyana Khaustova \\ Department of Food Technology \\ Kharkiv State University of Food Technology and Trade \\ 333 Klochkivska str., Kharkiv, Ukraine, 61051 \\ haustenok@ukr.net \\ Natalia Fedak \\ Department of Food Technology \\ Kharkiv State University of Food Technology and Trade \\ 333 Klochkivska str., Kharkiv, Ukraine, 61051 \\ fedaknv@ukr.net \\ Svetlana Andrieieva \\ Department of Food Technology \\ Kharkiv State University of Food Technology and Trade \\ 333 Klochkivska str., Kharkiv, Ukraine, 61051 \\ svetana783@ukr.net \\ Aliona Dikhtyar \\ Department of Food Technology \\ Kharkiv State University of Food Technology and Trade \\ 333 Klochkivska str., Kharkiv, Ukraine, 61051 \\ alenadikhtyar@ukr.net
}

\begin{abstract}
The aim of the research is to study a behavior of the viscosity of model systems of the croquette mass, based on flour, in the wide diapason of shift velocities depending on temperature and duration of hydrothermal processing (HTP). Realization of this aim allows to get products with set parameters of quality and safety, provides the rational use of raw material resources, reduces the labor intensity of the technological process of making culinary products of the croquette mass.

It was found out, that a temperature and duration of HTP have an essential influence on formation of rheological characteristics of the croquette mass. It was revealed, that model systems reach the maximal viscosity at temperature $70{ }^{\circ} \mathrm{C}$ in $20 \ldots 30$ min, at $80{ }^{\circ} \mathrm{C}$ - in $5 \ldots 10 \mathrm{~min}$. But the structure formation finishes at $70{ }^{\circ} \mathrm{C}$ in 20 minutes, at $80^{\circ} \mathrm{C}-$ in 10 minutes. Research data allow to reveal a possibility of regulating rheological characteristics of the croquette mass, based on flour, at the expanse of varying HTP parameters. It provides prognostication of a behavior and set form stability of the croquette mass at the contact with the technological equipment at making culinary products.

Prospects of further studies in this direction are the investigation of an influence of technological factors of HTP on the form stability and structural-mechanical characteristics of the croquette mass, based on flour.

Keywords: croquette mass, based on flour; viscosity, rotation viscosimeter, hydrothermal processing, shift value.
\end{abstract}

\section{Introduction}

In food systems, including the croquette mass, proteins and starch have an essential influence on physical-chemical and technological properties of a ready product $[1,2]$. It is obvious, that rheological properties of protein-carbohydrate complexes, including viscosity, are one of technological characteristics that determines both parameters of the technological process and consumption properties of ready products. For example, work [3] is devoted to studying changes of rheological properties of wheat dough depending on its structure and hydration. Results of research [4] demonstrated that triglycerides, added to starch suspensions, 
influenced the process of gelatinization, rheological behavior and stabilization of systems at heating. And within work [5] there is studied the influence of hydrothermal processing of wheat flour on properties of starch and proteins for raising its functionality, optimization of the temperature regime of processing, stabilization of the liquid-viscous phase. Work [6] studies the influence of HTP parameters on wheat flour properties, demonstrates that HTP makes wheat flour suitable as a stiffener.

Within the study the croquette mass based on wheat flour is a semi-product, received by HTP of flour fried with a fat component, with further adding taste-aromatic components and filler, used for making culinary products, fried in deep fat.

More practical importance is inherent to studies of mechanical properties of the croquette mass and their changes at the contact with equipment surfaces.

One of most important stages of formation of consumption properties of culinary products of the croquette mass is formation of the necessary structure that depends not only on the content of recipe components, but also on duration of hydrothermal processing (HTP) of the croquette mass.

Taking into account the data of paste formation and stability coefficient of model systems $[2,6]$, temperature parameter of HTP of wheat flour is accepted as $70 \ldots 80{ }^{\circ} \mathrm{C}$ according to the temperature of reaching the maximal viscosity of samples taking into account guaranteeing parameters of microbiological stability of the croquette mass.

This fact is a base for realizing studies of the viscosity of model systems of the croquette mass in the wide shift diapason. These data are necessary at forecasting the completeness of internal processes in the croquette mass and its behavior at the contact with the technological equipment in the process of making culinary products.

The aim of the study was to determine the influence of hydrothermal processing parameters on the viscosity of a model system of the croquette mass, based on flour. It allows to set the influence of HTP parameters on structural-mechanical parameters and on form stability of the croquette mass. It gives a possibility to create products with new consumption properties and ways of formation, decrease of labor intensity and mechanization of the technological process of making culinary products of the croquette mass.

According to the set aim, it is necessary to solve the following tasks:

- to determine the dependence of viscosity of non-disturbed and disturbed structure of systems of the croquette mass on HTP duration at temperature $70{ }^{\circ} \mathrm{C}$;

- to reveal the dependence of viscosity of non-disturbed and disturbed structure of systems of the croquette mass on HTP duration at temperature $80{ }^{\circ} \mathrm{C}$;

- to study the dependence of viscosity of non-disturbed and disturbed structure of systems of the croquette mass based on flour on HTP time for fixed values of shift velocities.

\section{Materials and Methods}

The study of the viscosity of croquette mass systems, based on flour, was realized using a wide-diapason rotation viscosimeter with a regulated shift velocity (gradient) $[1,7]$.

The dynamic or effective viscosity was determined by the formula:

$$
\eta=\frac{\alpha \cdot z}{\gamma}
$$

where $\alpha$-deviation angle on the viscosimeter scale, degrees; $\mathrm{z}$ - cylinder constant, Pa for unit of the scale, $\gamma$-shift velocity, $\mathrm{s}^{-1}$.

The shift velocity was determined by the formula:

$$
\eta=\frac{2 \pi N r^{2}}{\mathrm{R}^{2}-\mathrm{r}^{2}}
$$

where $\mathrm{N}$ - rotation frequency of a rotor, $\mathrm{s}^{-1} ; \mathrm{r}$ - rotor radius, $\mathrm{m} ; \mathrm{R}$ - cylinder radius, $\mathrm{m}$. 
At realizing this study at the direct orientation of the growth of the shift gradient value, there were considered the viscosity of the non-disturbed structure $\eta_{0}$, reverse - disturbed $\eta_{\mathrm{M}}$, hysteresis ratio of the viscosity of the non-disturbed structure to the one of the disturbed one $\left(\eta_{0} / \eta_{\mathrm{M}}\right)$.

\section{Experimental procedures}

For studying the viscosity, there were prepared model systems of the croquette mass, based on fried flour (with flour content $10 \%$, margarine $-8,8 \%$, vegetable oil $-4,4 \%$, cow milk $2,5 \%$, fat $-76,8 \%$ ). At preparing samples of model systems and their preparation to the studies, the temperature can influence the structure formation. Just that is why as a result of the experimental studies and observations, there was chosen a way, at which a sample is placed in a cylinder hot, at that the viscosity hysteresis value increases several times. And viscosities were equal in the area for the disturbed structure directly and reversely. The characteristic of samples of the croquette mass, based on flour, is presented in Table 1.

Table 1

Characteristic of samples of the croquette mass, based on flour, depending on hydrothermal processing parameters

\begin{tabular}{|c|c|c|}
\hline \multirow{2}{*}{ HTP duration, $\tau(\times 60), s$} & \multicolumn{2}{|c|}{ Characteristic of model systems at HTP temperature } \\
\hline & $70^{\circ} \mathrm{C}$ & $80^{\circ} \mathrm{C}$ \\
\hline 0 & Mixture of recipe components & Mixture of recipe components \\
\hline $3-5$ & $\begin{array}{l}\text { Mixture of recipe components. Signs of the be- } \\
\text { ginning of paste formation process are observed }\end{array}$ & $\begin{array}{c}\text { Mass already has signs of flexible and elastic } \\
\text { properties }\end{array}$ \\
\hline 10 & Soft elastic mass & Soft elastic mass \\
\hline 15 & Soft elastic mass & Soft elastic mass, inessential separation of fat \\
\hline 20 & Soft elastic mass, inessential separation of fat & $\begin{array}{c}\text { Soft elastic mass, inessential separation of fat. } \\
\text { Layering of the mass }\end{array}$ \\
\hline 30 & Soft mass. Layering of the system is observed & $\begin{array}{l}\text { Soft mass, essential separation of fat. Layering of } \\
\text { the system }\end{array}$ \\
\hline
\end{tabular}

The statistical processing of the results, construction of graphs were made using STATISTICA 13.3 software (in packaging of Process Optimization) and MS Office Excel 2010.

\section{Results}

4. 1. Study of the dependence of viscosity of non-disturbed and disturbed structure of systems of the croquette mass on HTP duration at temperature $70{ }^{\circ} \mathrm{C}$

Preliminary studies of the influence of technological parameters on the protein and carbohydrate complex of wheat flour demonstrated that the frying process with a fat component results in disturbing the internal structure of starch and denaturation of proteins [8]. The studied model systems had a lower temperature of paste formation comparing with native flour.

For preparing model systems of the croquette mass, based on wheat flour, and studying their viscosity depending on HTP duration, the recommended temperature parameter was accepted within $70 \ldots 80^{\circ} \mathrm{C}$.

Fig. 1, 2 present dependencies of the viscosity of model systems of the croquette mass, based on flour, at HTP temperature $70^{\circ} \mathrm{C}$ under conditions of increasing and decreasing the shift value. The data of Fig. 1, 2 indicate that model systems at temperature $70^{\circ}$ are non-Newtonian liquids, which viscosity depends on the shift velocity.

On Fig. 2 (curve $10 \mathrm{~min}$ ) we can observe the abrupt growth of viscosity at decreasing the shift velocity that is probably connected with formation of the structure from small shift velocities. At HTP during 15 and $20 \mathrm{~min}$ (Fig. 1, 2 curves $10 \mathrm{~min}, 15 \mathrm{~min}$ ) the least inclination angle of curves $\eta(\gamma)$ is observed that testifies to formation of the firmer structure. With increasing the shift velocity, 
there is observed the decrease of the system viscosity, taking place probably as a result of destructing the structural net and aggregates of particles and their orientation along the velocity vector that is typical for non-Newtonian liquid $[1,2]$.

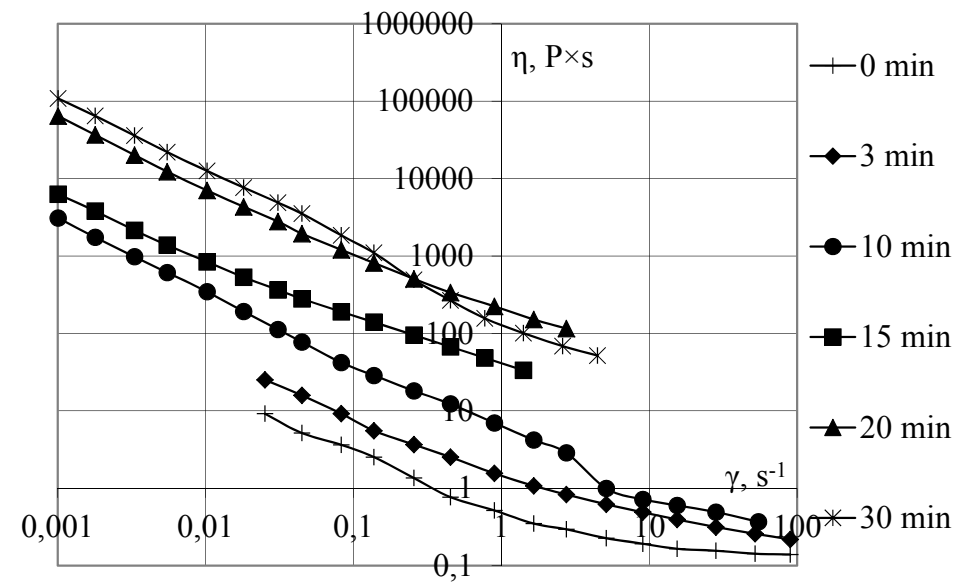

Fig. 1. Viscosity of the non-disturbed structure (direct course) of model systems of the croquette mass at temperature $70^{\circ} \mathrm{C}$ depending on HTP duration at changing the shift value

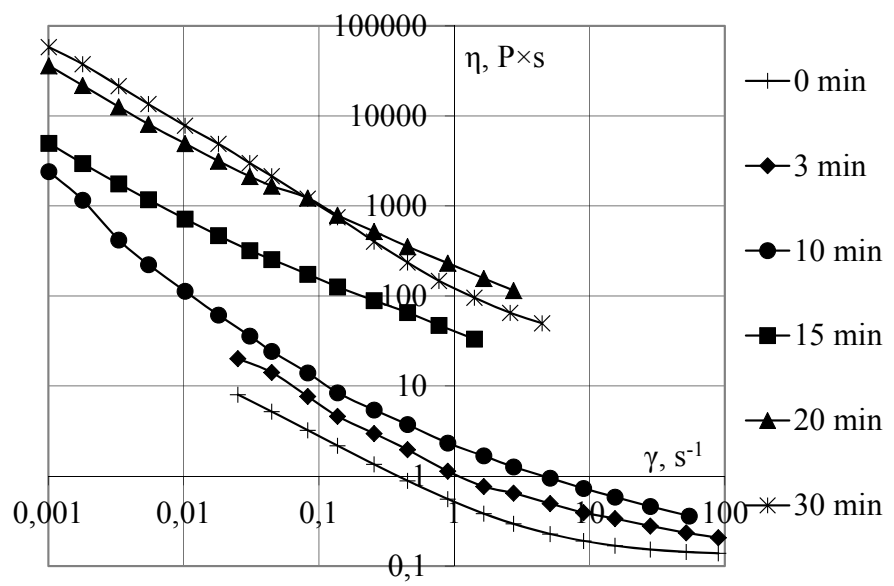

Fig. 2. Viscosity of the non-disturbed structure (reverse course) of model systems of the croquette mass at temperature $70{ }^{\circ} \mathrm{C}$ depending on HTP duration at changing the shift value

These data are testified by literary ones [5, 7-10], with the temperature increase, fluctuations of starch molecules in grains increase, intermolecular connections disintegrate that results in their stronger interaction between each other and water molecules through nitrogen connections.

4. 2. Study of the dependence of viscosity of non-disturbed and disturbed structure of systems of the croquette mass on HTP duration at temperature $80{ }^{\circ} \mathrm{C}$

The dependence of viscosity of model systems of the croquette mass at boiling temperature $80{ }^{\circ} \mathrm{C}$ somewhat differs from the one for model systems at boiling temperature $70{ }^{\circ} \mathrm{C}$.

From the data on Fig. 3, 4 we can see that the least inclination angle belongs to the curve that corresponds to $10 \mathrm{~min}$ of HTP that is the process of structure formation finishes. At HTP of the system as $80^{\circ} \mathrm{C}$ for more than $15 \mathrm{~min}$, there is observed some layering of the structure (in becomes heterogenic, fat secretions from the system). On Fig. 3, 4 this process can be observed at the abrupt decrease of viscosity at shift tensions more $0,1 \mathrm{~s}^{-1}$, that results in the growth of the inclination angle of the viscosity curve from the shift. There is also observed approximately twice more viscosity hysteresis than at $\mathrm{HTP}$ at $70{ }^{\circ} \mathrm{C}$ that is there takes place the stronger disintegration of the initial structure. 


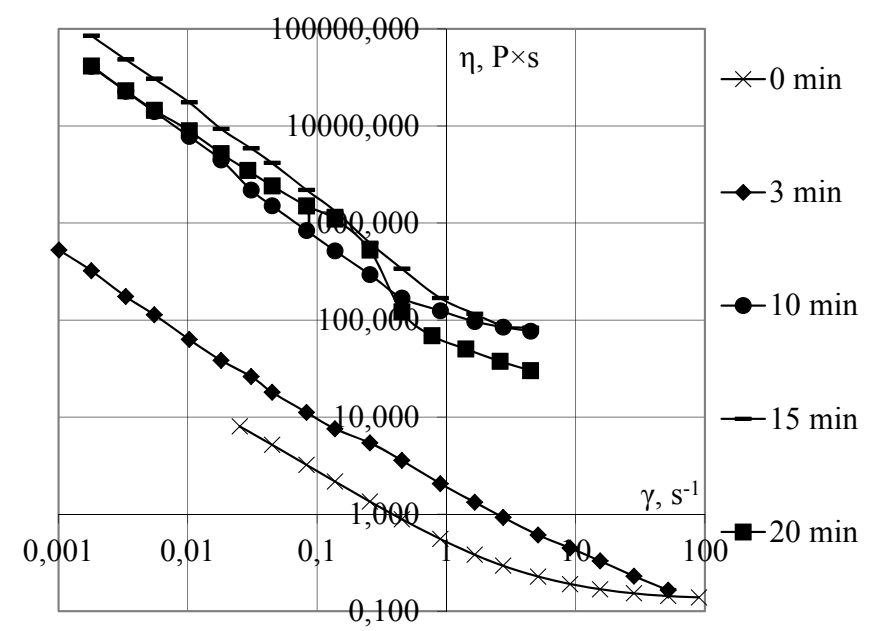

Fig. 3. Viscosity of the non-disturbed structure (direct course) of model systems of the croquette mass at temperature $80{ }^{\circ} \mathrm{C}$ depending on HTP duration at changing the shift value

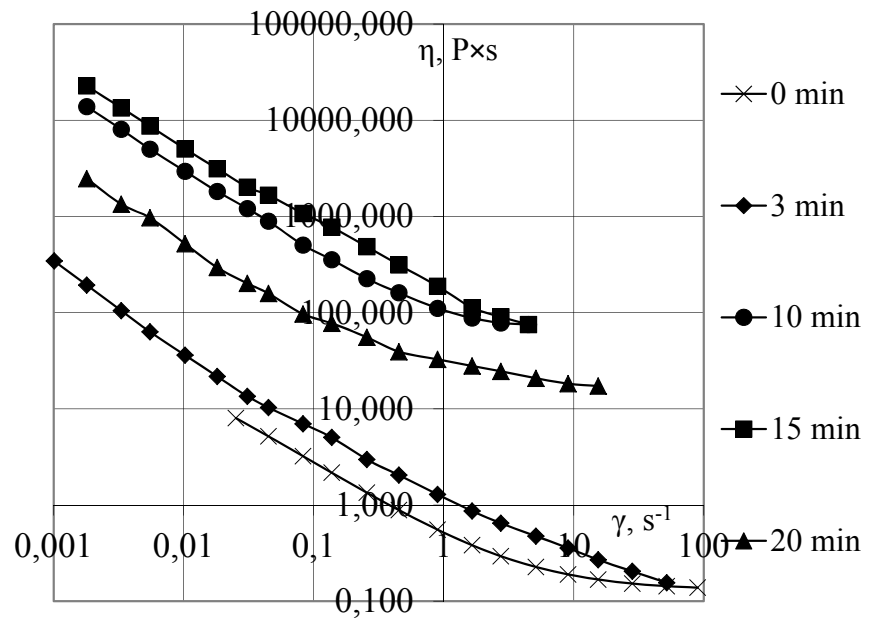

Fig. 4. Viscosity of the non-disturbed structure (reverse course) of model systems of the croquette mass at temperature $80{ }^{\circ} \mathrm{C}$ depending on HTP duration at changing the shift value

4. 3. Study of the dependence of viscosity of model systems of the croquette mass based on flour on HTP time for fixed values of shift velocities

Fig. 5 presents the results of the study of model systems of the croquette mass based on flour on HTP time for fixed values of shift velocities. The viscosity grows by two-three orders at HTP that probably testifies to the change of intermolecular forces at the expanse of paste formation of starch and hydration of hydrocolloids of flour.

According to the data of Fig. 5, at the low shift velocities $\gamma=0,045 \mathrm{~s}^{-1}$ and HTP temperature $70{ }^{\circ} \mathrm{C}$ viscosity reaches maximum in $20 \mathrm{~min}$ and at $80{ }^{\circ} \mathrm{C}-5 \mathrm{~min}$ that correlates with the time of structure formation of these systems. At the shift velocities $\gamma=1,65 \mathrm{~s}^{-1}$ (Fig. 5, b) the viscosity growth takes place faster in systems at $70{ }^{\circ} \mathrm{C}$ HTP and reaches its maximum value in 20 minutes. The abrupt growth of viscosity of the studied systems with HTP temperature $80^{\circ} \mathrm{C}$ at less time indicates the intensive process of paste formation of starch.

The results of the study allow to formulate the following conclusions:

- the study of the dependence of viscosity of non-disturbed and disturbed structure of systems of the croquette mass on HTP duration at temperature $70{ }^{\circ} \mathrm{C}$ indicates that the process of structure formation finishes in $20 \mathrm{~min}$, and at temperature $80^{\circ} \mathrm{C}-$ in 10 minutes. These data provide a possibility to stabilize structural-mechanical parameters of the croquette mass, allow to 
prognosticate and to influence HTP process at mechanization of the process of its preparation by regulating a duration and temperature;

- the study of the dependence of viscosity of model systems of the croquette mass based on flour on HTP time for fixed values of shift velocities $\left(\gamma=0,045 \mathrm{~s}^{-1}, \gamma=1,65 \mathrm{~s}^{-1}\right)$ demonstrated the maximization of viscosity in 20 minutes at $70{ }^{\circ} \mathrm{C}$, in $5 \ldots 10$ minutes at $80^{\circ} \mathrm{C}$. The research results allow to state about determining the mechanism of changing viscosity of the croquette mass depending on HTP parameters that is a certain advantage from the practical point of view for the substantiated approach to the process of mechanization of making products of the croquette mass.

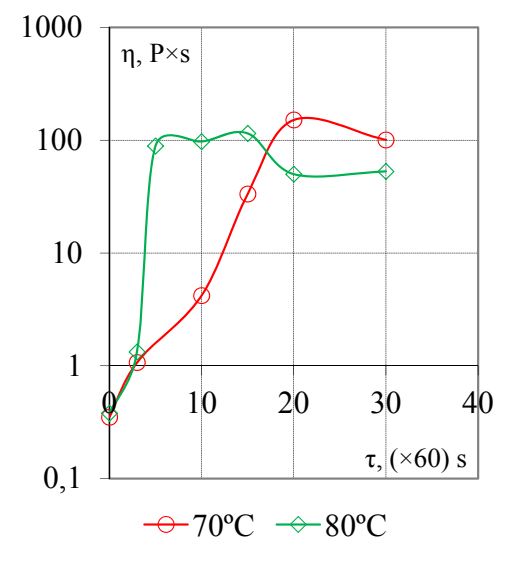

a

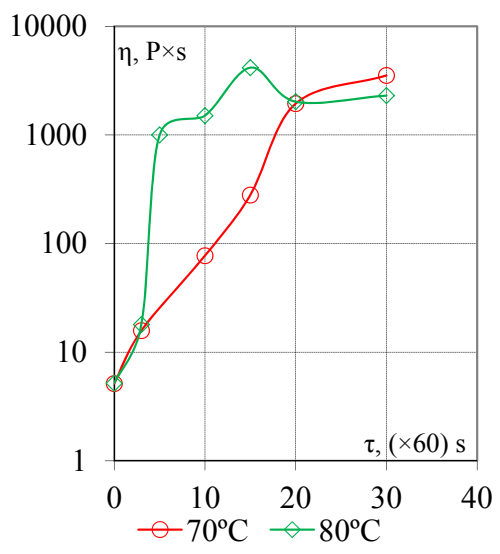

$b$

Fig. 5. Viscosity of model systems of the croquette masses based on flour depending on HTP duration at temperature $70{ }^{\circ} \mathrm{C}, 80{ }^{\circ} \mathrm{C}$ at shift velocity: a $-0,045 \mathrm{~s}^{-1} ; b-1,65 \mathrm{~s}^{-1}$

The obtained results allow to control the process of creating the structure of the croquette mass based on flour by correcting HTP parameters (increase or decrease its temperature and duration).

The obtained experimental dependencies may be used for optimization of HTP and obtaining of the croquette mass with set structural-mechanical parameters and form stability. It allows to control HTP and gives a possibility to provide mechanization of the process of producing the croquette mass, based on flour.

\section{Conclusions}

The conducted researches have established that a temperature and duration of HTP have an essential influence on formation of rheological characteristics of the croquette mass. There has been revealed a possibility of regulating rheological characteristics of the croquette mass, based on flour, at the expanse of varying HTP temperature and duration parameters. At $70{ }^{\circ} \mathrm{C} \mathrm{HTP}$ the structure formation finishes in $20 \mathrm{~min}$, at $80^{\circ} \mathrm{C}$ - in $10 \mathrm{~min}$. 
But it must be noted, that the results of viscosity determination indicate the ambiguous influence of HTP temperature and duration on rheological characteristics of model systems. It is manifested, in the first turn, in open questions as to studying structural-mechanical parameters and form stability of the croquette mass. Prospects of further studies in this direction are the investigation of an influence of technological factors of HTP on the form stability and structural-mechanical characteristics of the croquette mass, based on flour.

\section{References}

[1] Aret, V. A., Rudnev, S. D. (2014). Reologiya i fiziko-mekhanicheskie svoystva pishchevyh produktov. Sankt-Peterburg, 246.

[2] Arana, I. (Ed.) (2012). Physical Properties of Foods. Novel Measurement Techniques and Applications. CRC Press Taylor \& Francis Group, 412.

[3] Bucsella, B., Takács, Á., Vizer, V., Schwendener, U., Tömösközi, S. (2016). Comparison of the effects of different heat treatment processes on rheological properties of cake and bread wheat flours. Food Chemistry, 190, 990-996. doi: https://doi.org/10.1016/j.foodchem.2015.06.073

[4] Chiotelli, E., Rolée, A., Le Meste, M. (2004). Rheological Properties of Soft Wheat Flour Doughs: Effect of Salt and Triglycerides. Cereal Chemistry Journal, 81 (4), 459-468. doi: https://doi.org/ 10.1094/cchem.2004.81.4.459

[5] Lazaridou, A., Marinopoulou, A., Biliaderis, C. G. (2019). Impact of flour particle size and hydrothermal treatment on dough rheology and quality of barley rusks. Food Hydrocolloids, 87, 561-569. doi: https://doi.org/10.1016/j.foodhyd.2018.08.045

[6] Khaustova, T., Fedak, N., Andreeva, S., Dihtyar, A. (2018). Studying the influence of hydrothermal treatment parameters on the properties of wheat flour in the technology of a croquette mass. Eastern-European Journal of Enterprise Technologies, 6 (11 (96)), 77-82. doi: https://doi.org/10.15587/17294061.2018.150072

[7] Malafaiev, M. T., Pohozhykh, M. I. (2007). Shyrokodiapazonnyi rotatsiynyi viskozymetr. Prohresyvni tekhnika ta tekhnolohii kharchovykh vyrobnytstv restrannoho hospodarstva $\mathrm{i}$ torhivli, 2 (6), 87-95.

[8] Chizhikova, O. G., Korshenko, L. O. (2016). Tekhnologiya proizvodstva hleba i hlebobulochnyh izdeliy. Moscow, 199.

[9] Keppler, S., Bakalis, S., Leadley, C. E., Sahi, S. S., Fryer, P. J. (2018). Evaluation of dry heat treatment of soft wheat flour for the production of high ratio cakes. Food Research International, 107, 360 370. doi: https://doi.org/10.1016/j.foodres.2018.02.041

[10] Nikolic, N., Dodic, J., Mitrovc, M., Lazic, M. (2011). Rheological properties and the energetic value of wheat flour substituted by different shares of white and brown rice flour. Chemical Industry and Chemical Engineering Quarterly, 17 (3), 349-357. doi: https://doi.org/10.2298/ciceq110203021n 